\title{
THE SERVICE OF REFRACTORY BLOCKS IN A SMALL EXPERIMENTAL GLASS TANK
}

\author{
By W. L. Pendergast and Herbert Insley ${ }^{1}$
}

\section{ABSTRACT}

Tests to determine the relative resistance of various types of refractories to the action of flowing molten glass were made in a small laboratory glassmelting furnace similar in shape and in operation to commercial scale continuous glass tanks. The results of tests made in nine runs of the furnace, each run continuing for approximately 30 days, are given. Clay tank block of commercial manufacture as well as blocks made of unusual compositions and by unusual processes were tested.

\section{CONTENTS}

I. Introduction

Page

II. Description of furnace

III. Method of testing

1. Composition of batch

2. Temperature measurements_--_---_-----_- 455

IV. Description of tests

1. Tank No. 1-_-_- 1

2. Tank No. 2_-----------

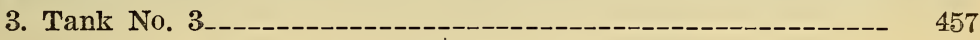

4. Tank No. 4

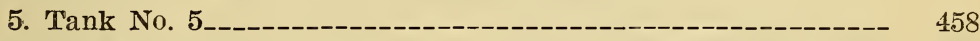

6. Tank No. 6_-_-_- 459

7. Tank No. 7---_- 459

8. Tank No. 8-_-

9. Tank No. 9-_- 961



\section{INTRODUCTION}

During the past few years there has been a marked tendency in the glass industry to increase the temperature for melting glass. This, naturally, has resulted in a more rapid disintegration of the refractory blocks used in the walls and other parts of continuous tanks. Moreover, refractory blocks from different manufacturers have shown

${ }^{1}$ Acknowledgments are due R. F. Geller for his part in this investigation. The program was outlined by him and the entire investigation up to and including the run of the ninth tank was under his direct supervision. 
widely different resistance to glass attack, and even blocks from the same manufacturer made apparently of the same materials and with the same processes have at times varied greatly in service.

While some theories have been advanced to account for the difference in resistance of different blocks, apparently little experimental work has been done to evaluate and correlate the factors that determine the degree of resistance of tank block to glass attack. The Bureau of Standards in 1924, therefore, inaugurated a laboratory investigation on commercial tank block with the hope that it would throw some light on the subject. For this purpose experimental, gas-fired, continuous glass tanks were constructed so that the tank blocks in the sides could be easily replaced. Nine melts were made between September, 1924, and October, 1927, using refractories prepared in the laboratory as well as blocks furnished by various manufacturers.

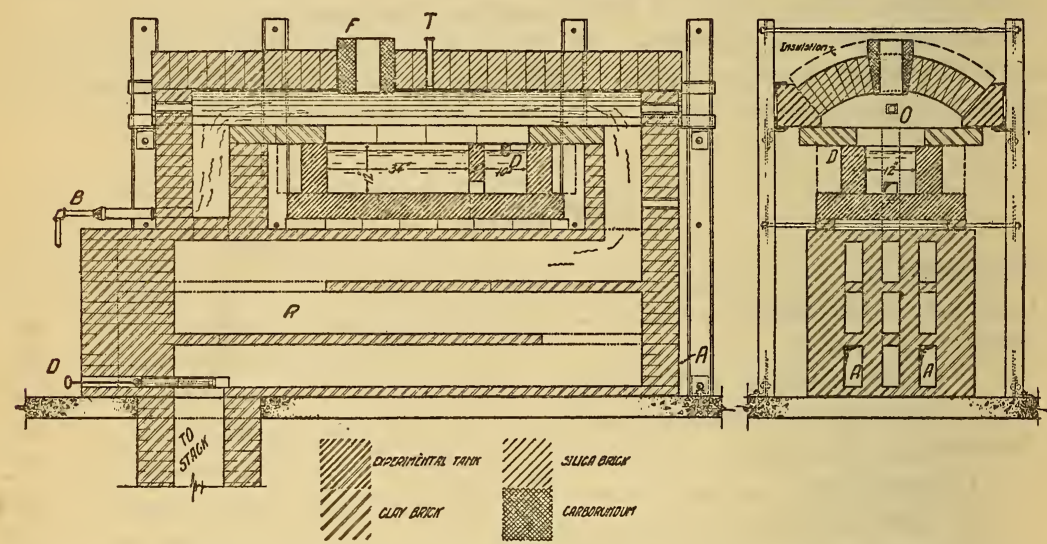

FIG. 1.-Drawing of furnace showing position of tanto and batch-feeding tube and the direction of gas flow

Glass was melted in each of the nine tanks, a test run continuing for approximatoly 30 days.

\section{DESCRIPTION OF FURNACE}

In its final form the furnace was a modified down-draft kiln, the gases burning while they passed horizontally over the tank. The furnace operated quite satisfactorily, considering that the fuel used was a carburetted water gas supplied for domestic use, averaging about 600 B. t. u. per cubic foot. Two burners with one-half-inch orifices were sufficient to maintain the required temperature. The tank itself was 12 inches high, 12 inches wide, and 4 feet long, the glass level being maintained about 2 inches from the top of the tank B. Batch was fed in at $F$ (fig. 1); the molten glass passed through the opening in the bridge wall and was drawn off at $D$. The crown was of silica brick with the exception of the carborundum block which 


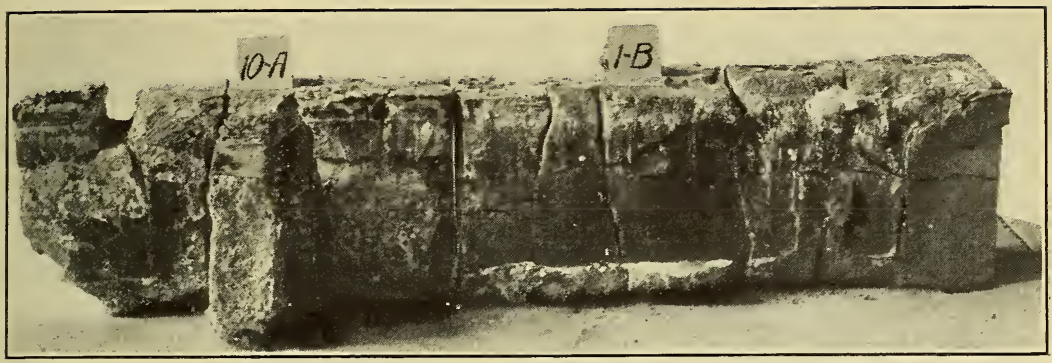

FIG. 2

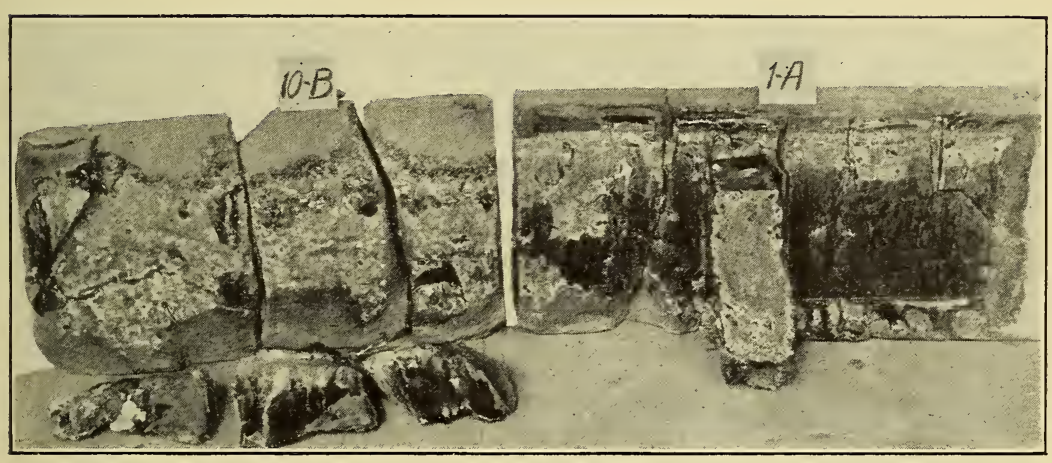

FIG. 3

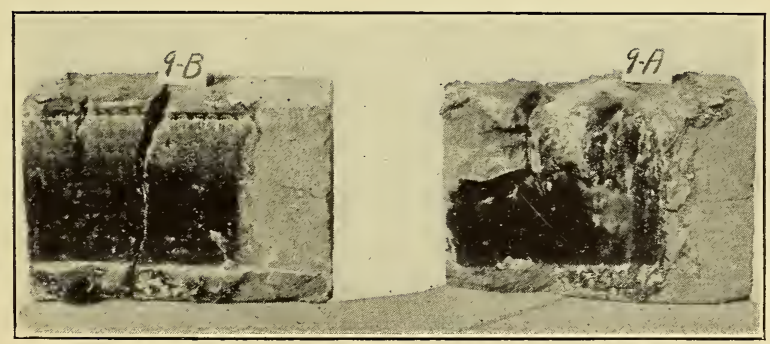

FIG. 4 
B. S. Journal of Research, RP44

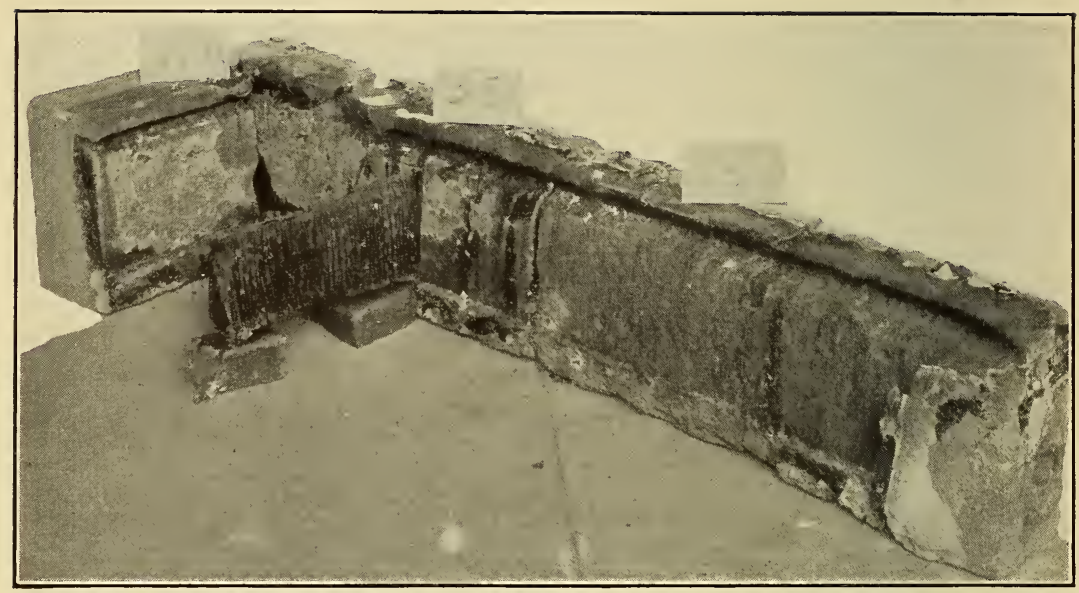

Fig. 5



FIG. 6 
contained the batch-feeding hole $F$ (fig. 1). The bottom blocks and tuck stones were made of a modified glass-pot body developed at the Bureau of Standards and composed of 50 per cent fire-brick grog burned to cone 16 and 50 per cent of unburned material. The unburned material was composed largely of Tennessee and Kentucky ball clays and North Carolina kaolin with minor amounts of Georgia and Delaware kaolins and feldspar.

\section{METHOD OF TESTING}

Batch fills of $121 / 2$ pounds each were made every 15 minutes during 8 consecutive hours. Results showed that the rate of glass movement under these conditions was sufficient to give marked corrosion with most refractory blocks at the end of 30 days' melting time.

\section{COMPOSITION OF BATCH}

The batch used was composed of 1,000 pounds of sand, 700 pounds of soda ash, 200 pounds of limestone, and 2 pounds of sodium nitrate. One part of cullet was mixed with three parts of batch.

The calculated chemical composition of the batch, based upon the proportions used and chemical analyses made of the soda ash and limestone, is $\mathrm{SiO}_{2} 66.3$ per cent, $\mathrm{Na}_{2} \mathrm{O}$ 26.8, $\mathrm{CaO}$ 4.0, and $\mathrm{MgO}$ 2.9. This batch is considerably higher in soda than the average soda-lime bottle glass batch and therefore more corrosive.

\section{TEMPERATURE MEASUREMENTS}

The temperatures during the melting period were read with an optical pyrometer which was sighted on the center of the arch. In one run four platinum, platinum-rhodium thermocouples were inserted through small holes in the side-wall blocks. Three of the couples were inserted midway of the length of the furnace, one at the surface of the glass, one near the bottom of the tank, and one halfway between. The fourth couple was 10 inches nearer the end wall of the melting chamber than the other three and at the bottom of the tank. A difference of about $50^{\circ}$ between couples at the bottom and top of the glass in the same vertical line was observed. The couple at the surface of the glass gave a temperature about $50^{\circ}$ lower than the optical when the optical read $1,550^{\circ}$ and about $40^{\circ}$ lower when the optical read $1,530^{\circ}$. 


\section{DESCRIPTION OF TESTS}

\section{TANK NO. 1}

The side walls of the first tank were built of six blocks furnished by three manufacturers. The blocks marked 1-A (fig. 3) and 1-B (fig. 2) were from the same manufacturer and were alike in composition and treatment except that $1-\mathrm{B}$ was reburned to cone 15 at the Bureau of Standards. All the blocks were 6 inches thick.

Since this was a first run, various unforeseen troubles arose which necessitated shutting down the furnace three times. Consequently, the time during which batch was melted was only 13 days. The average temperature during the melting period was $1,420^{\circ}$, and 3,800 pounds of batch were melted. The severity of service in this tank was considerably less than in any other tank in the series. Nevertheless, the blocks showed fairly severe corrosion. Figures 2 and 3 are photographs of the side-wall blocks arranged after dismantling the tank in the relative position which they occupied during the run. The bridge wall is toward the left in Figure 2 and toward the right in Figure 3. The end wall blocks are shown in Figure 4, the melting chamber end wall on the right and the refining chamber end wall on the left. All of the blocks showed serious spalling at the upper inside edges, probably because the furnace was shut down several times during the first three days of the test.

\section{TANK NO. 2}

The side walls of tank 2 were built of six commercial blocks, all 6 inches thick, furnished by three manufacturers. Block 1-I is the same as 1-L, except that the former was reburned to cone 15. (Figs. 5 and 6.) Batch was melted in this tank for 34 days at an average temperature of about $1,450^{\circ} \mathrm{C}$. Nine thousand pounds of batch were used. Although this average temperature was slightly higher $\left(25^{\circ}\right)$ than that of tank 9, the melting period was 10 per cent shorter and the amount of batch used 25 per cent less. (Table 1.) As affecting the amount of corrosion on tank walls, therefore, service conditions in tank 2 were probably slightly less severe than in tank 9 . Figure 5 is a photograph of one side wall, a portion of the bridge, and the refining end wall, and Figure 6 shows the other side wall and the melting end wall. The bridge-wall block, which was a commercial refractory, was partially destroyed, but all the side-wall blocks were quite free from pits and corrugation and showed little evidence of corrosion except at the glass line. Even at the glass line the depth of corrosion was not great as compared with that in most of the other tanks in the series. The commercial block reburned to cone 15 showed 9.2 per cent absorption as compared with 13.0 per cent absorp- 
B. S. Journal of Research, RP44

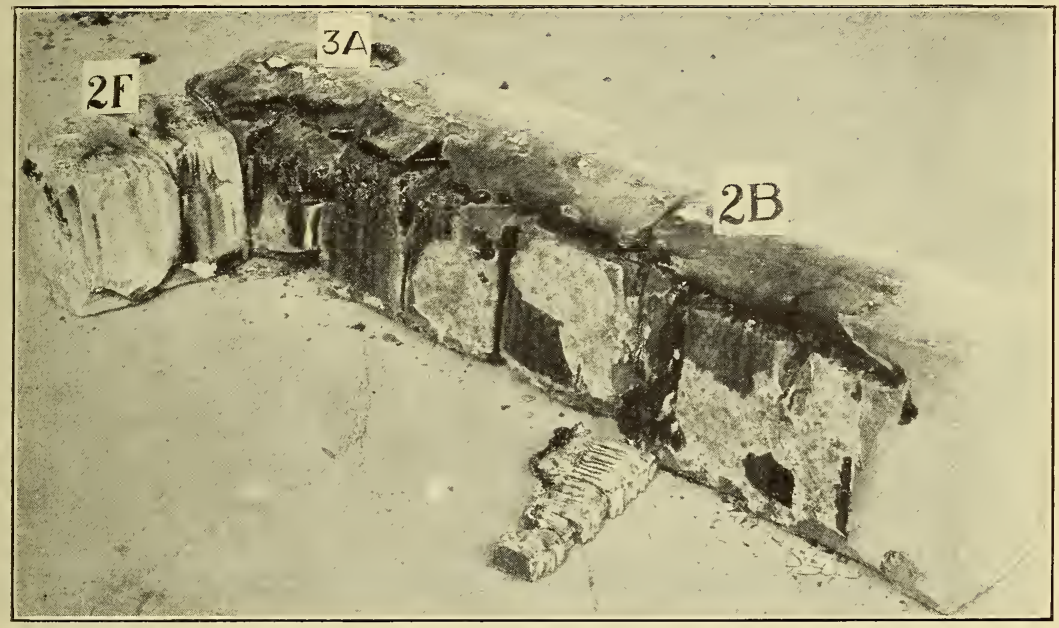

FIG. 7

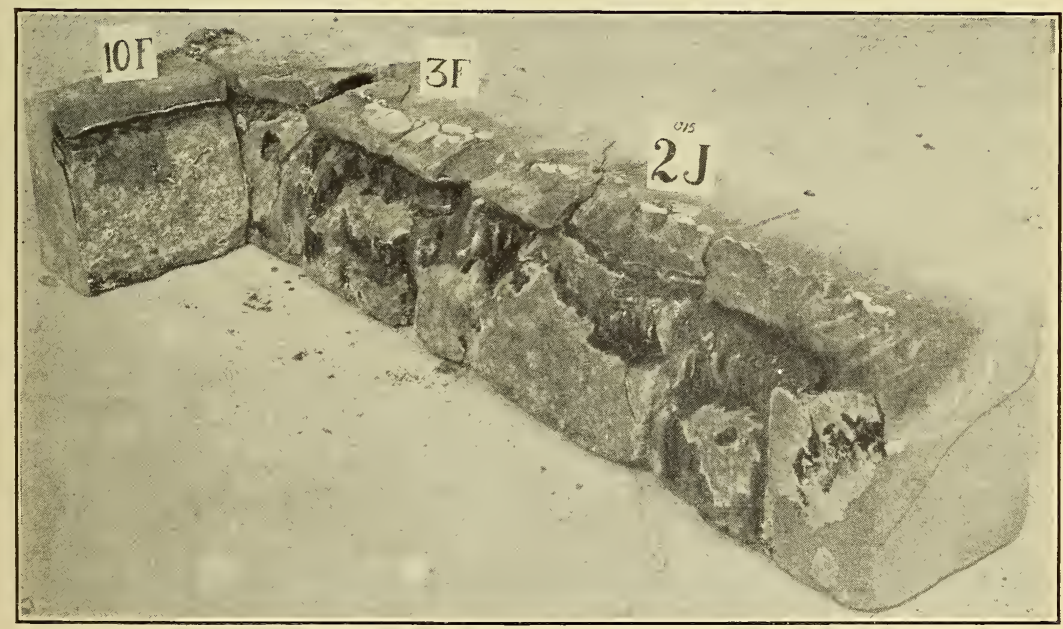

Fig. 8 
B. S. Journal of Research, RP44

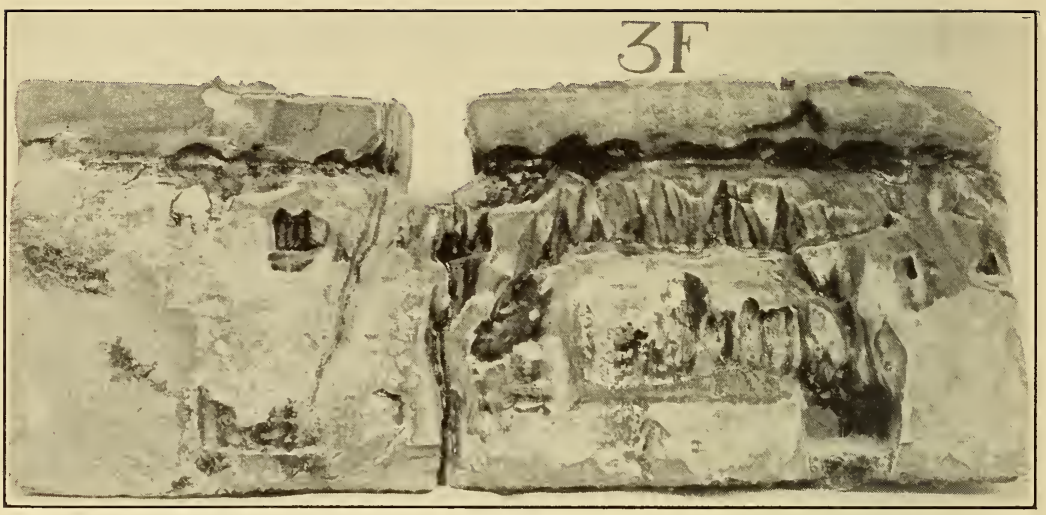

FIG. 9

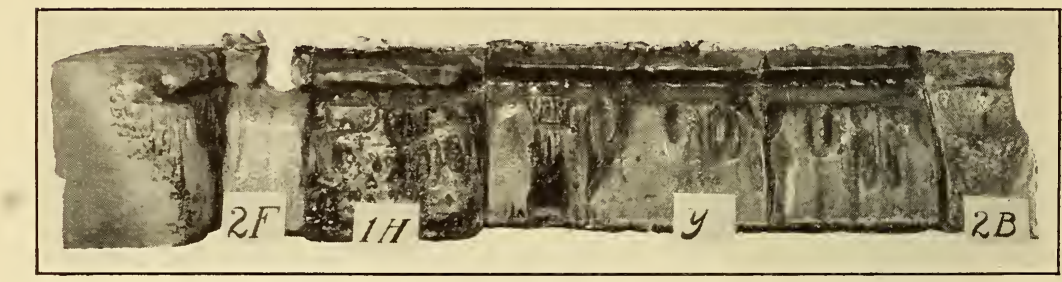

FIG. 10

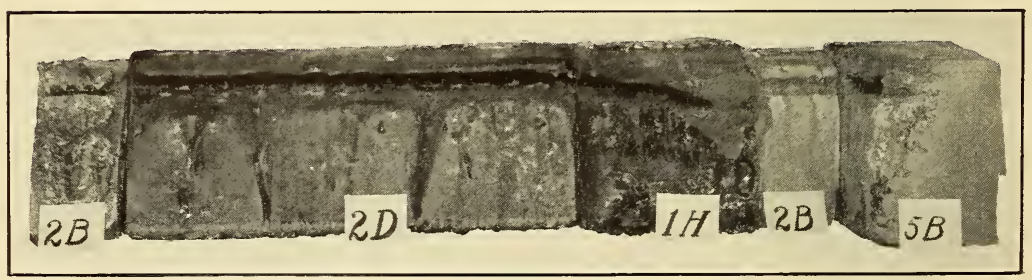

FIG. 11 
tion for the block of the same manufacture not reburned. The reburned block also showed a slightly greater resistance to glass attack.

\section{TANK NO. 3}

The six blocks making up the side walls of tank 3 were from three manufacturers, and the bridge wall also was a piece of a commercial block. During a melting period of 26 days the tank was operated at an average temperature of $1,525^{\circ} \mathrm{C}$, and approximately 9,000 pounds of batch were used. Although the average operating temperature was about as high as for any tank in the series, the melting period was unusually short. Consequently, the severity of service was less than for tanks 4,5 , and 6 , and may be considered as about equal to tank 7. Figure 7, a photograph of one side wall, the melting-chamber end wall, and a detached piece of the bridge, shows the marked effects of glass attack on the end wall and the blocks in the melting end of the tank. Figure 8 is a photograph of the other side of the tank with the refining-chamber end wall. The bridge was eaten through and broken away from the side walls, and the indentation at the glass line was greater than 2 inches on all the blocks in the melting end of the tank and reached a maximum of $33 / 4$ inches on block 2J. (Fig. 8.) Block 2J showed more attack than any other block in the tank. This was in large part due to the presence of vertical and horizontal cracks or laminations which provided starting places.

Corrosion upward from horizontal cracks, so characteristic of the action in many commercial tanks, ${ }^{2}$ is well exemplified in blocks $3 \mathrm{~F}$ (fig. 9), $3 \mathrm{~A}$ (fig. 7), and $2 \mathrm{~F}$ (fig. 7). Block $2 \mathrm{~F}$ was also worn back greatly above the glass line. It should be noted that this block contained more silica (73 per cent) than any other wall block used in this series of experiments.

One sample of each of the following materials was dropped into the melting chamber of tank 3 and left there until the end of the run:

A. Fused quartz disk (13 ounces).

B. Cylinder of calcined alumina and kaolin (approximately 50 per cent $\mathrm{SiO}_{2}, 50$ per cent $\mathrm{Al}_{2} \mathrm{O}_{3}$ ) burned to $1,400^{\circ}$ in three hours (20 ounces).

C. Fire-clay brick (38 ounces).

D. Sandstone block (70 ounces).

E. Fused alumina block (46 ounces).

F. High alumina ( 80 to 85 per cent $\mathrm{Al}_{2} \mathrm{O}_{3}$ ) block (55 ounces).

${ }^{2}$ Ross, D. W., Wearing Away of Tank Blocks, J. Am. Ceram. Soc., 9, pp. 641-654; 1926. 
All the specimens had dissolved or disintegrated except the fused alumina block, which was reduced to about one-half the original size and the high alumina block which was reduced to one-quarter the original size.

\section{TANK NO. 4}

Tank 4 was built of commercial blocks, all 8 inches thick. It was run for a melting period of 36 days at an average temperature of $1,525^{\circ} \mathrm{C}$., and 13,000 pounds of batch were used. This tank undoubtedly had the sererest service of any in the series. All the blocks were greatly worn both at and below the glass line. Figure 10 shows one side wall and a part of the refining end wall, Figure 11 the other side wall and a part of the melting end wall. In the melting chamber the arerage depth of erosion at the glass line was 5 inches and below the glass line more than 1 inch. In blocks $Y$ and $2 D$ irregular vertical channels and horizontal benches were formed which began at cracks. Although blocks marked " $2 \mathrm{~B}$ " were very badly worn, they showed no evidence of cracks or laminations. The difference in depth of corrosion on these blocks and the adjoining ones is well shown in Figure 12. The bridge wall although 11 inches thick was almost entirely eaten away below the glass line. (Fig, 13.)

\section{TANK NO. 5}

Tank 5 mas built of six commercial blocks and three special blocks. Of the latter one (GP) was made of a glass pot body using firebrick grog, and the other two (marked "BS30") were made from batch furnished by a block manufacturer which was made up and fired to cone 15 at the Bureau of Standards. The tank was operated during a period of 35 days at an average temperature of $1,525^{\circ} \mathrm{C}$., and 11,000 pounds of batch were melted. The conditions in this tank were only slightly less serere than in tank 4.

The blocks in the melting chamber (on the right in fig. 14 and on the left in fig. 15) showed marked effects of glass action. Block 8A is unusual in that it shows numerous, repeated, vertical flutings or corrugations. The deeper channels due to pronounced vertical cracks or laminations can also be obserred. Block GP was worn to a depth of 5 inches at the glass line. Below the glass line the surface in contact with the glass was honeycombed with pits. (Figs. 15 and 16.) In places these pits extended to within 2 inches of the cool surface. The pitting may be ascribed to a combination of rather high porosity and to easy solubility in the glass. Although the blocks contain only about 56 per cent of silica, the percentage of fluxes present is rather high, about 3 per cent. One of the blocks made at the Bureau of Standards from a manufacturer's batch was used in 
B. S. Journal of Research, RP44

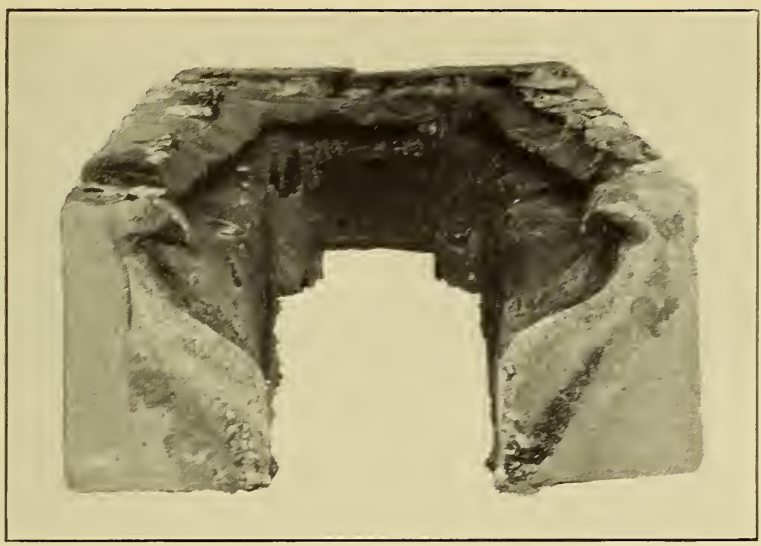

FIG. 12

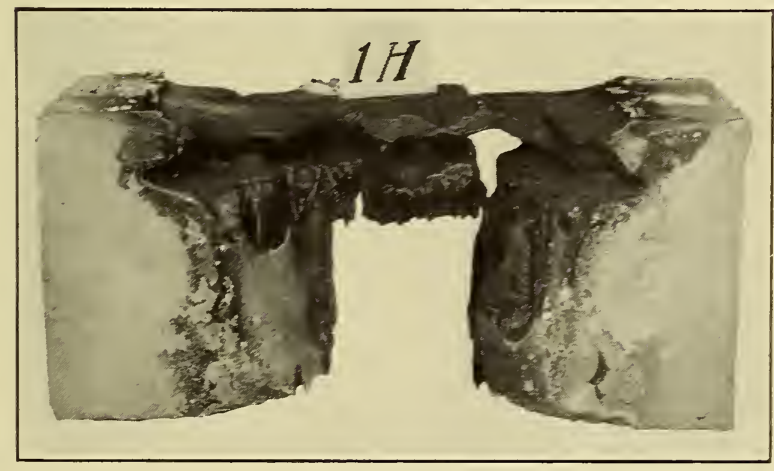

FIG. 13

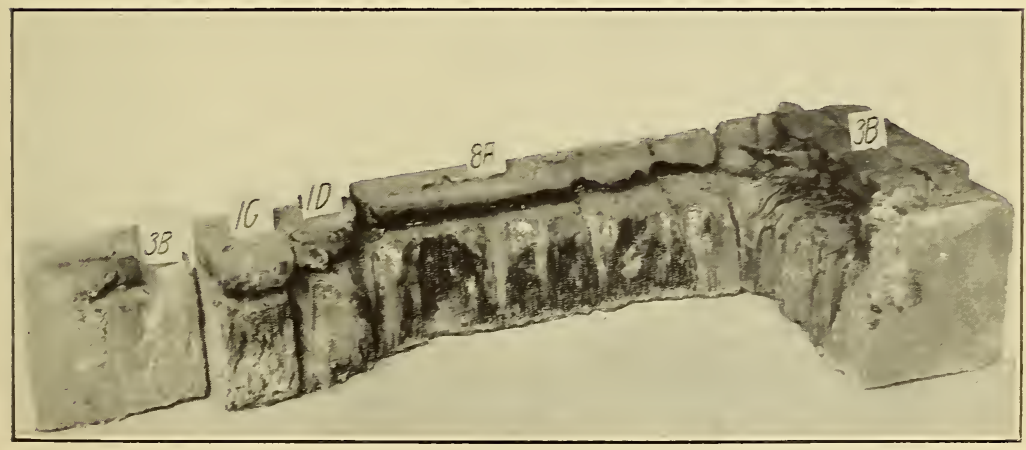

FIG. 14 
B. S. Journal of Research, RP44

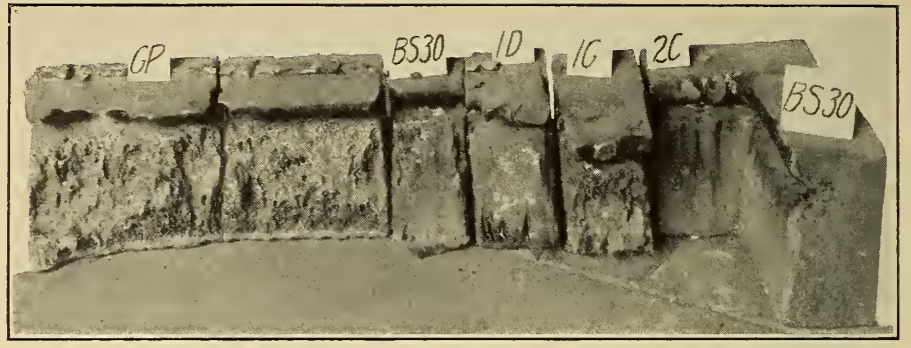

FIG. 15

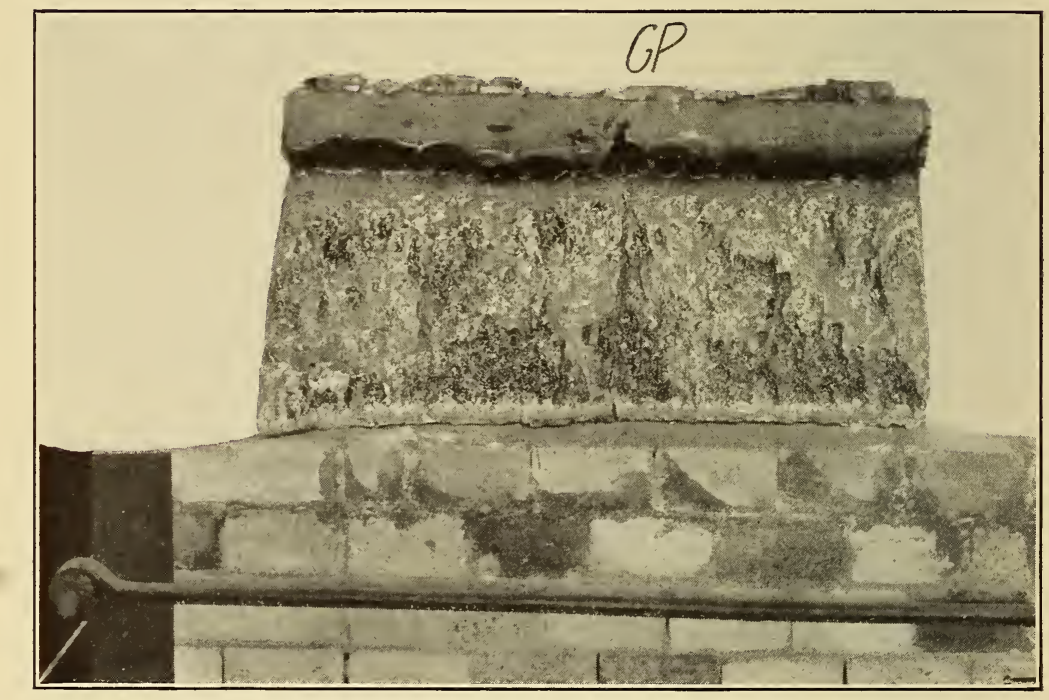

FIG. 16

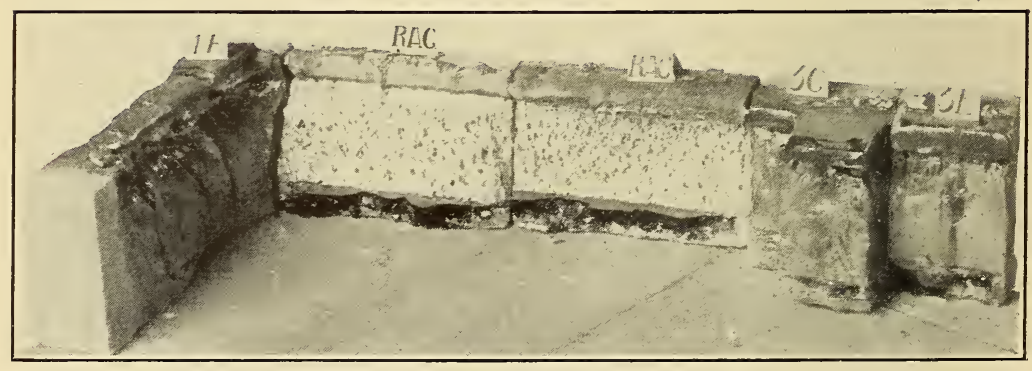

FIG. 17 
the melting chamber. (BS30 in fig. 15.) It withstood corrosion very well, but its position next to the bridge wall was particularly favorable.

\section{TANK NO. 6}

The walls and bridge of tank 6 were built of 5 commercial and 5 experimental blocks. All the blocks were 6 inches thick except the bridge block, which was 10 inches. The tank was operated for 36 days at an average temperature of $1,500^{\circ} \mathrm{C}$., and 12,000 pounds of batch were melted. While the average temperature was $25^{\circ}$ lower than in tank 5, the amount of batch used was slightly greater. Of particular interest were the tests on the experimental blocks. The blocks marked RAC (fig. 17) were composed of artificial corundum (made by electric furnace fusion) of 14 mesh or finer. The alumina grains were bonded with 10 per cent clay and burned. As Figure 17 shows, these blocks were badly honeycombed and eaten away. The depth of indentation at the glass line was about 3 inches. The blocks marked RSC (fig. 18) were composed of crystalline mullite (made by electric furnace fusion) of 14 mesh or finer. The mullite grains were bonded with kaolin and alumina in the proportions to give mullite and fired. The mullite blocks were also badly corroded and honeycombed, although the pits were much smaller than in the alumina blocks. (Fig. 19.)

An experimental block 3 inches thick composed largely of spinel $\left(\mathrm{MgO} \cdot \mathrm{Al}_{2} \mathrm{O}_{3}\right)$ was placed in the tank as a part of the bridge wall. It formed the portion of the bridge wall in the melting chamber and was backed by a clay block 7 inches thick. The only remaining fragment of this block is marked MA. (Fig. 18.) It seems probable from this evidence that spinel is readily attacked by molten soda-lime glass. Although the clay portion of the bridge (3C, fig. 18) was eaten through, it withstood glass attack far better than the spinel.

\section{TANK NO. 7}

The walls of the melting chamber of tank 7 were built of two alumina blocks, two mullite blocks, and one block (forming the end wall) of a commercial batch burned to cone 15 at the Bureau of Standards. The bridge wall was made of two blocks, back to backa Georgia kaolin block burned to cone 15 at the Bureau of Standards facing the melting chamber and a block of commercial batch burned to cone 15 at the bureau facing the refining chamber. The side walls of the refining chamber were two commercial blocks of the same brand, and the end block was of Georgia kaolin burned at the Bureau of Standards.

The tank was operated for 37 days at an average temperature of $1,450^{\circ} \mathrm{C}$., and 12,000 pounds of batch were melted. Due to the lower 
temperature, service conditions were somewhat less severe than in $\operatorname{tank} 6$.

The blocks marked RAF (fig. 20) were of the same composition (90 per cent artificial corundum, 10 per cent clay) as the blocks RAC in $\operatorname{tank} 6$, but the alumina was much finer grained. Of this pair the block on the right was originally 6 inches thick from the bottom to a horizontal line about 4 inches from the top. Above the line the inside face was beveled off, so that the glass surface made an oblique angle with the face of the block. The block on the left was 4 inches thick below the horizontal line shown in the photograph and 6 inches above. The latter block was made in this way to furnish a readymade horizontal downward facing surface where the characteristic "upward eating" could take place if the block were susceptible to it. Figure 20 shows some evidence of this action. The fine-grained alumina blocks offered much greater resistance to glass action than did the coarser-grained blocks. (Figs. 17 and 19.) The alumina blocks in tank 7 were eaten back about 1 inch at the glass line. No pitting was visible on the surface exposed to glass action.

The mullite blocks (RSF in fig. 21) were the same as the mullite blocks in tank 6 except for increased fineness of grain. Here, again, the finer-grained blocks showed a marked improvement in resistance to glass action. The left-hand block in Figure 21 was corroded to a depth of 1 inch at the glass line, the right-hand block to a depth of 2 inches. In general, there was little wearing away below the glass line, although in the left-hand block there are two cracks along which marked corrosion had taken place. These cracks may have formed during the heating period in the tank before glass melting began. The Georgia kaolin blocks forming the end wall in the refining chamber and a part of the bridge wall are seen in Figure 21 (GA-1 and GA-2). The end wall was corroded at the glass line to a depth of $2 \frac{1}{2}$ inches and was very badly pitted below the glass line. The portion of the bridge wall composed of the kaolin block was eaten through from bottom to top and was also badly pitted. Needless to say, such a test does not give a fair idea of the solubility of burned kaolin in molten glass. The structure was necessarily very open, and apparently disintegration of the block was caused primarily by entrance of molten glass into the pores.

\section{TANK NO. 8}

All of the blocks in the melting chamber of tank 8 were experimental with the exception of the end wall. The tank was operated for 27 days at an average temperature of $1,450^{\circ}$ C., and approximately 11,000 pounds of batch were melted. Although the average melting temperature was $25^{\circ}$ higher in tank 8 than in tank 9 , the duration of run and the amount of batch melted were considerably 
B. S. Journal of Research, RP44

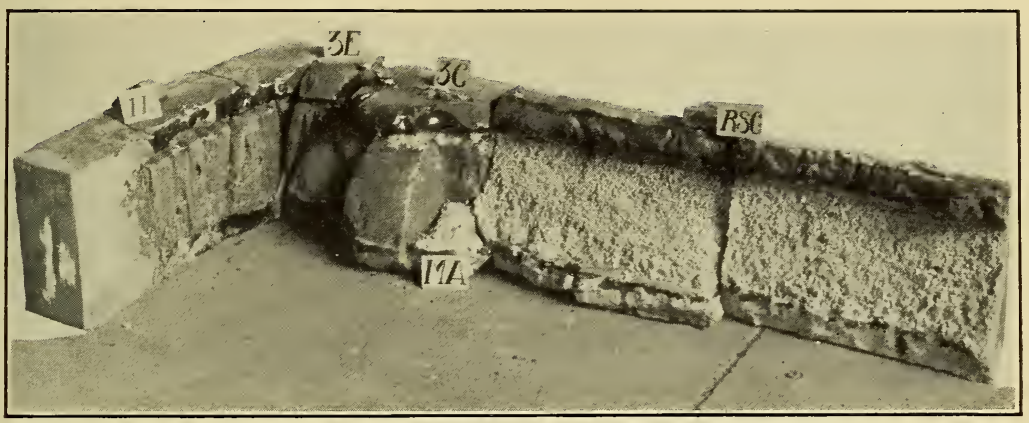

FIG. 18

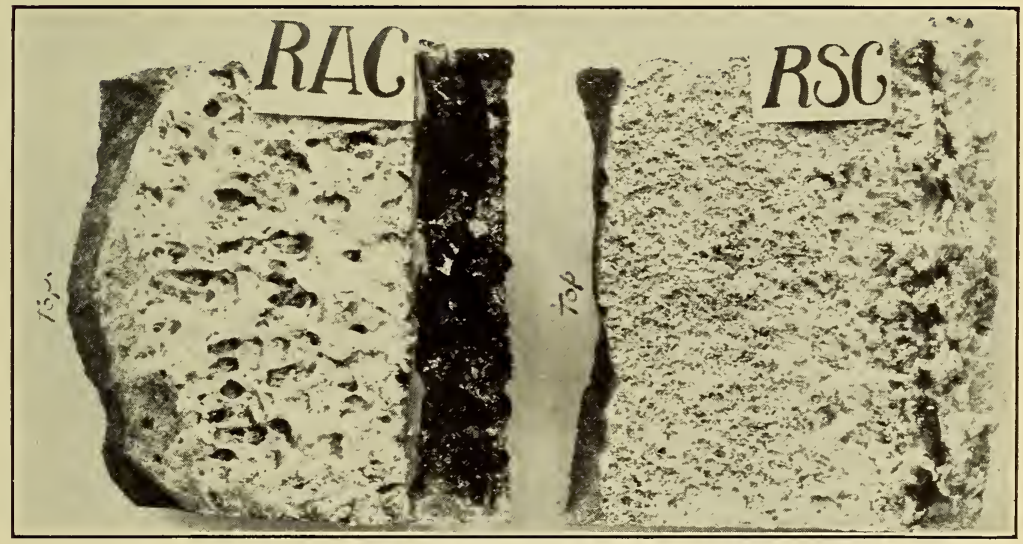

FIG. 19

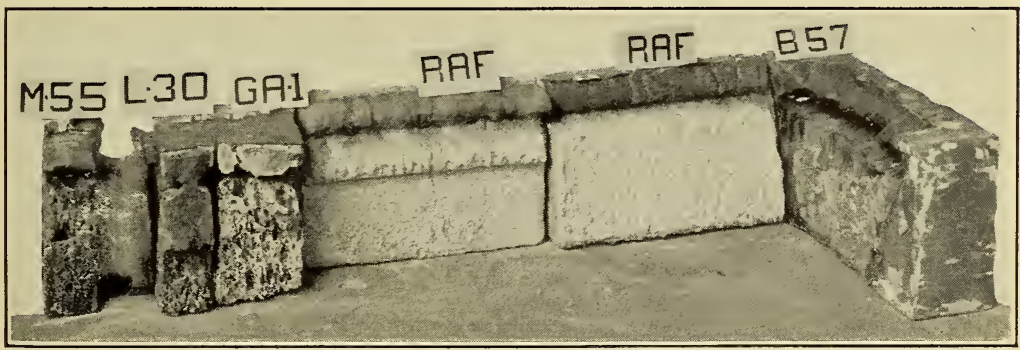

FIG. 20 
B. S. Journal of Research, RP44



FIG. 21



FIG. 22



FIG. 23 
B. S. Journal of Research, RP44

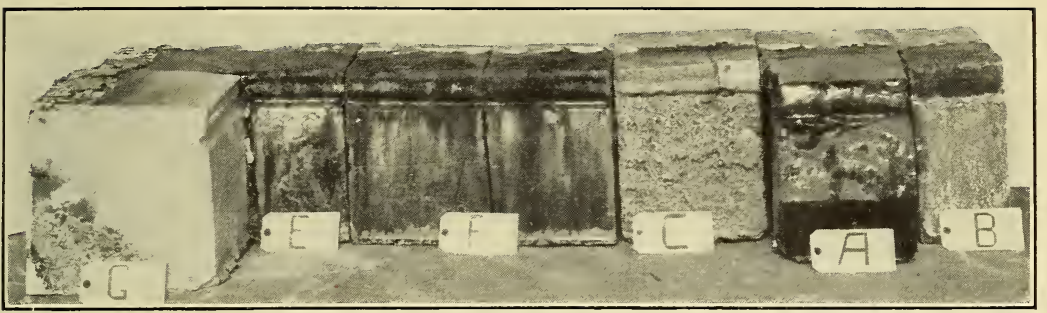

FIG. 24

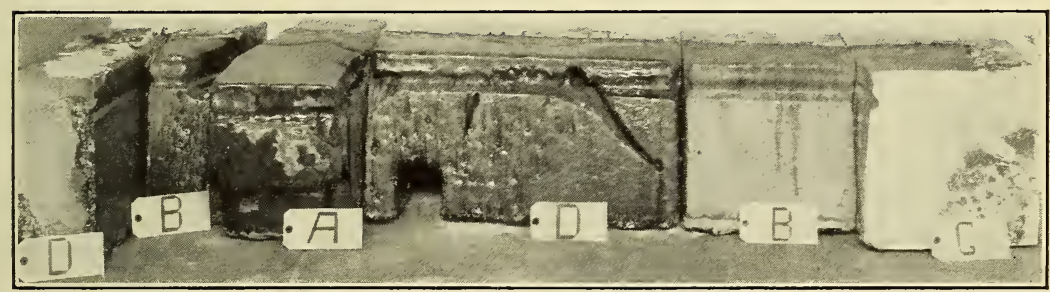

Fig. 25

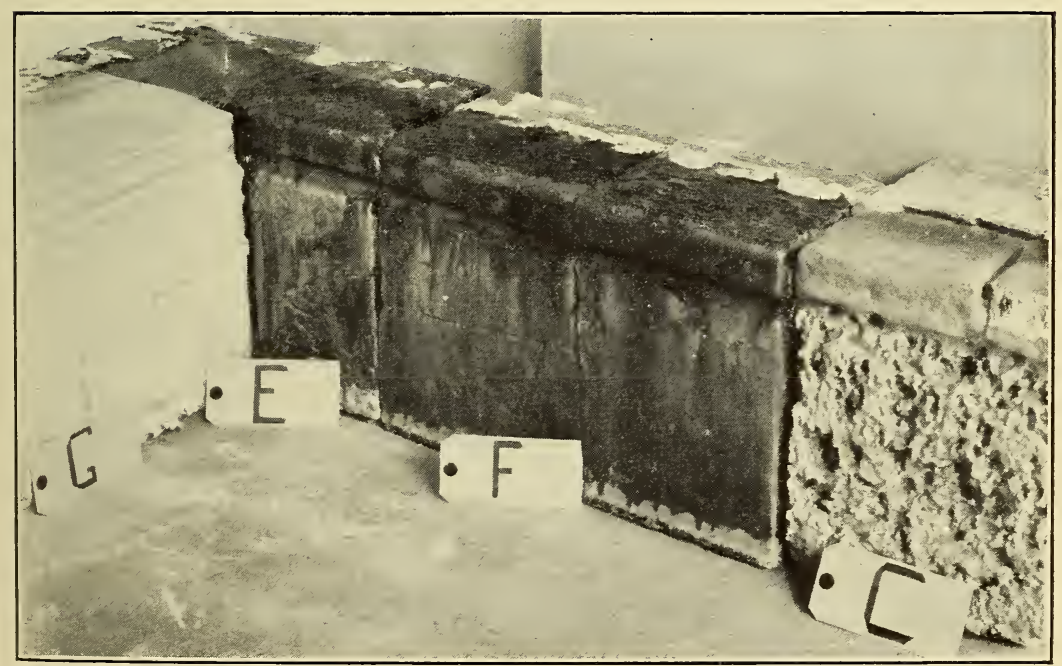

FIG. 26 
less than in the latter, and the severity of service can be considered approximately the same in the two tanks.

The blocks in the side walls of the melting chamber (figs. 22 and 23) resisted glass action unusually well, probably in part because the operating conditions were not as severe as in some of the runs. The commercial block in the end wall of the melting chamber (H2), however, showed as much wear as end blocks in runs where operating conditions were more severe.

Blocks M-2 (fig. 22) and M-1 (fig. 23) were dry-pressed blocks made wholly of Missouri flint clay. The grog, composing 45 per cent of the block, was burned to cone 14 at a plant manufacturing tank block, shipped to the bureau, where the raw clay was added, dry pressed at 1,500 lbs./in. ${ }^{2}$, and burned to cone 16 . These blocks were worn $1 \frac{1}{2}$ inches at the glass line and were in comparatively good condition at the end of the run. Block M-3 (fig. 22) was a handmade diaspore block, burned to cone 16 . It was worn to a depth of $1 \frac{1}{2}$ inches at the glass line and apparently was similar to $M-2$ in resistance to glass action. Block A-1-2 (fig. 22) was an experimental hand-rammed block made of calcined cyanite. Although it showed fair resistance to glass action and was worn only $11 / 2$ inches at the glass line, it was badly pitted and contained one long curved crack along which marked corrosion took place. Block 35 (fig. 23) was made of the same material as block A-1-2 but was dry-pressed to 3,500 lbs./in. ${ }^{2}$ instead of hand rammed. As the photograph indicates, this block withstood glass action much better than A-1-2, the pits were few and small, and there were no cracks. Block $\mathrm{K}$ was made of the glass pot batch used in the bottom blocks and tuck stones in all the experimental tanks, but was dry pressed to 850 lbs./in. ${ }^{2}$ instead of being hand rammed. The block was in good condition after the run except for a large crevice probably formed during the burning of the block or the heating up of the tank.

\section{TANK NO. 9}

All the blocks in the walls of tank 9 are of the so-called "special refractory " type, with the exception of the bridge, which was built of a commercial clay tank block, and block $\mathrm{D}$, which is a commercial clay block fabricated by an unusual process.

This tank was operated at an average temperature of $1,425^{\circ}$ for 38 days, during which time 12,000 pounds of batch were melted. While conditions in this tank were less severe than in tanks $4,5,6$, and 7, they were probably approximately the same as in tanks 2 and 8. (Table 1.) Tank 2 was operated at an average temperature $25^{\circ}$ higher than tank 9 , but considerably less batch was melted. In tank 8 the average temperature was also $25^{\circ}$ higher than in tank 9 , but the duration of the run was much shorter. 
The effect on the wall blocks is seen in Figures 24, 25, and 26. Block $\mathrm{A}$, the bridge wall, is a commercial clay block. It shows severe corrosion, but considering that the bridge wall in many runs was almost wholly eaten away, it resisted glass action remarkably well.

Block C (figs. 24 and 26) was a special refractory. Petrographic examination showed that it was composed largely of very minute crystals of mullite in glass with a little granular corundum. Apparently a large part of the mullite and glass had been formed by the dissociation of cyanite, since large aggregates of minute needles of mullite and glass contained remnants of undissolved cyanite grains at their centers. This block was badly pitted after service and showed the least resistance to corrosion of any block in the tank. Disintegration probably resulted more from porous structure or from lack of homogeneity than from chemical composition. Blocks $\mathrm{E}$ and $\mathrm{F}$ (figs. 24 and 26) were from the same manufacturer and were made, it is understood, of an electrically fused mixture containing alumina and silica in the proper proportions to form mullite.

After use in the furnace the blocks were broken in half and specimens chipped from several places on the fractured faces. Petrographic examinations of these chips gave the following results: Block $\mathrm{E}$ was found to be composed of mullite $\left(3 \mathrm{Al}_{2} \mathrm{O}_{3} \cdot 2 \mathrm{SiO}_{2}\right)$, corundum $\left(\mathrm{Al}_{2} \mathrm{O}_{3}\right)$, glass and opaque material. In all the chips examined mullite was the most abundant constituent, although the relative amount present varied from place to place in the block. Corundum varied from 10 to 30 per cent. Glass in small amounts was observed in channels between the mullite crystals. The opaque material occurred as lenticular masses and dendritic growths included in both mullite and glass. Chips from block $\mathrm{F}$ were composed largely of corundum with small amounts of glass, mullite, and an unidentified compound with very high index of refraction and high double refraction. Corundum occurred in large, well-formed crystals and was evidently the first compound to crystallize. The mullite crystals, although very small, were well developed and were inclosed in glass. In all probability crystallization of the mullite took place after the corundum.

These two blocks showed greater resistance to glass attack than any of the other blocks in this series of tests. The indentation at the glass line was only one-half to five-eighths of an inch with a maximum corrosion at the center of the block of about one-fourth inch. Block E cracked some time after installation. The surface also shows some checking. Block $F$ was partially cracked when received, and the cracks continued through the block during test. Glass attack at the cracks in these blocks was not appreciably more than at any other part of the surface of the block below the glass line. (Fig. 26.) 
Block $G$ used as the end wall of the melting chamber was a special refractory. Petrographic examination showed that it was composed of fairly coarse grains of corundum and mullite with interstitial glass. The interstitial glass often contained well-developed needles of mullite. The structure suggests that the block is composed of mullite and corundum formed by electrical fusion afterwards bonded with an aluminum silicate (perhaps clay) and fired to a rather high temperature. Although the block was in a position in the furnace where corrosive action of the melt was pronounced, it showed excellent resistance to such action. There was an indentation at the glass line of about an inch, while the center of the exposed face was corroded only about one-half inch. Four cracks developed in the same block some time after installation, but glass attack along these cracks was not excessive.

Block B was a special refractory composed, according to petrographic examination, of corundum, andalusite and quartz in fairly coarse grains, corundum and andalusite being the most abundant constituents. The edges of the andalusite grains were converted to a mixture of mullite and glass. This block also withstood glass attack exceptionally well. A few very small pits were found in the face of the block, and the indentation at the glass line was only about an inch.

Block D is a clay block which, it is understood, received a somewhat unusual treatment before burning. This block compared favorably with the best clay blocks previously tested. The block was eaten away at the glass line to a depth of $1 \frac{1}{4}$ inches. A few small pits developed in the face and one fairly large oblique crack, which was further enlarged by glass attack.

\section{DISCUSSION OF RESULTS}

Any attempt to make direct comparisons between blocks used in different tanks or even in the same tank is not justified. A review of the photographs of the blocks after use shows at once that blocks in different positions in the same tank were not exposed to the same corrosive action. In general, the bridge wall received the most severe treatment. Blocks in the melting chamber were exposed to much more severe conditions than those in the refining chamber, and of the former the end-wall position was the worst. Next in order are the side-wall blocks nearest the end wall and then the side-wall blocks nearest the bridge.

Table 1 is useful in estimating the relative severity of conditions in the different tanks. It is evident that conditions were not the same in all the tanks, and that consequently a block from one tank can not always be compared with a block from any other tank even though 
the blocks occupied the same positions. However, the table shows that tanks 5 and 6 are comparable in operating conditions as are tanks 2, 8, and 9. Tank 4 had the most severe treatment.

\section{TABLE 1}

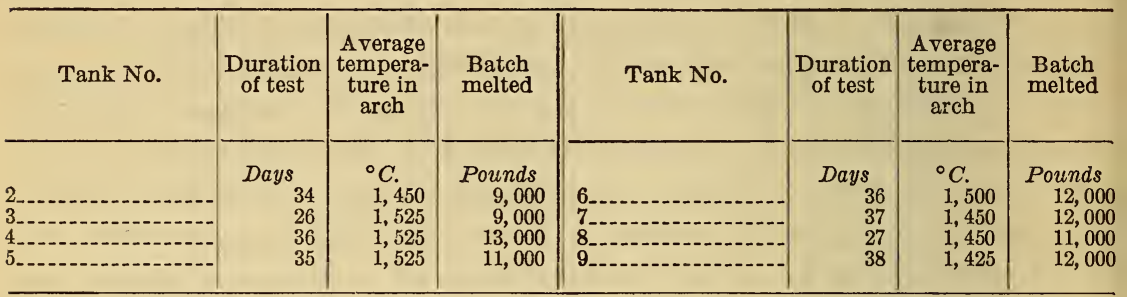

Chemical analyses and absorption determinations were made on most of the blocks used (Table 2), but in general there appears to be little relation between either chemical composition or porosity and resistance to glass attack. The effect of homogeneity of a refractory on its resistance to glass must be considerable, and as yet no satisfactory means of measuring homogeneity has been devised. Many instances of distintegration of tank blocks by pitting are shown in the photographs. Such pitting may be the result of (1) the presence of numerous coarse pores in the block, (2) a decided difference in composition between grog and bond, or (3) lack of adherence between the particles in the refractory. To be able to determine by physical and chemical tests alone the resistance of a refractory to glass action, suitable methods of measuring the properties enumerated above must be devised, and the relative importance of these properties in providing resistance to the action of molten glass must be determined. 
TABLE 2

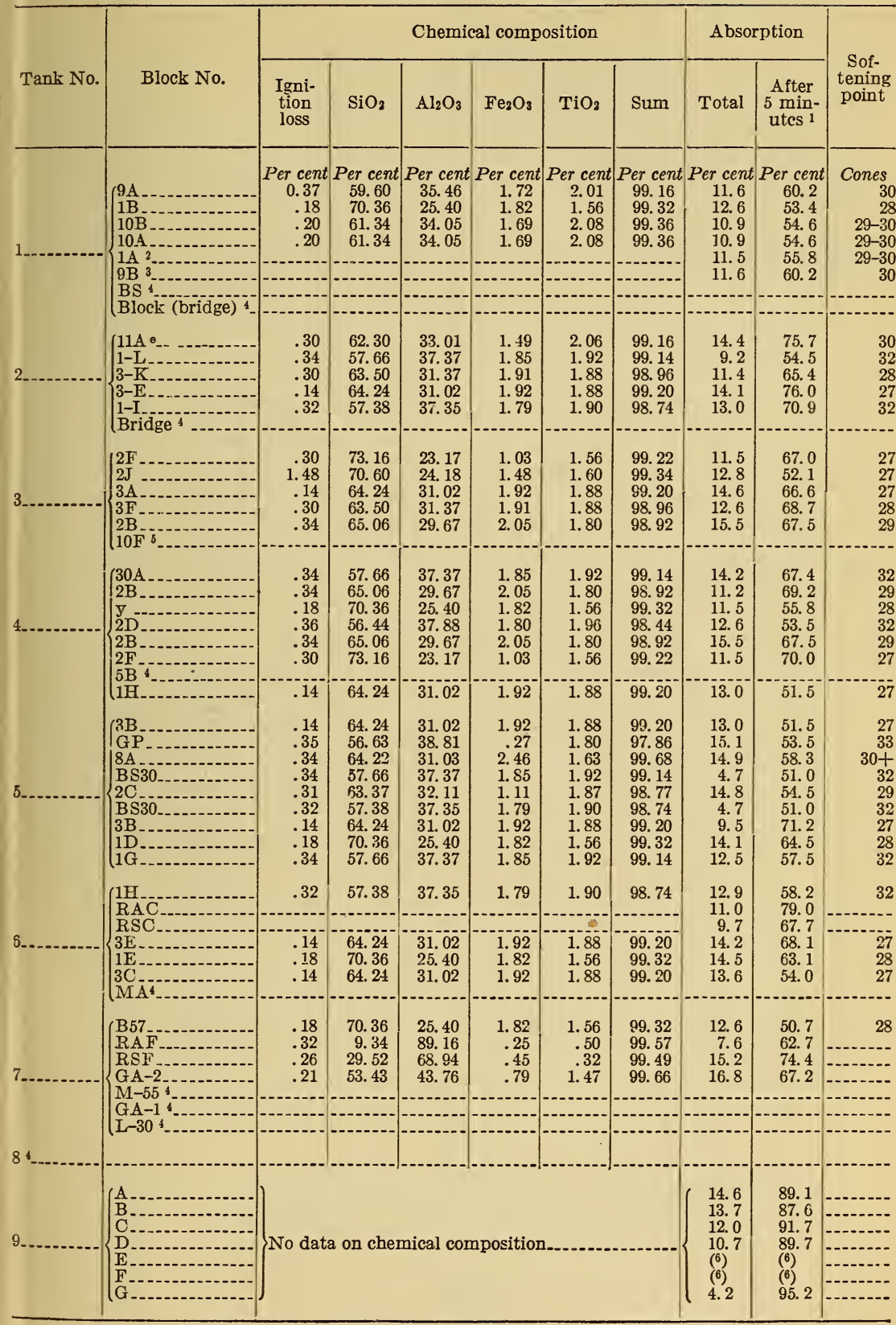

1 Expressed as percentage of total absorption.

2 Analysis same as $1 \mathrm{~B}$.

analysis same as $9 \mathbf{A}$.

WASHINGton, September 12, 1928 ,
4 No data.

5 Same as $10 \mathrm{~B}$

$\checkmark$ Negligible. 